\title{
METEORS: A DELIVERY MECHANISM OF ORGANIC MATTER TO THE EARLY EARTH
}

\author{
PETER JENNISKENS AND MIKE A. WILSON \\ NASA/Ames Research Center, Mail Stop 239-4, Moffett Field, CA 94035 \\ E-mail: pjenniskens@mail.arc.nasa.gov
}

\section{DENNIS PACKAN, CHRISTOPHE O. LAUX \\ AND CHARLES H. KRÜGER}

High Temperature Gasdynamics Laboratory, Building 520, Mechanical Engineering

Department, Stanford University, Stanford, CA 94305-3032

\author{
IAIN D. BOYD
}

Department of Aerospace Engineering, University of Michigan, 3012 Francois-Xavier Bagnoud Building, Ann Arbor, MI 48109-2140.

OLGA P. POPOVA

Institute for Dynamics of Geospheres RAS, Leninsky prospekt 38, bld.6, Moscow 117979, Russia

and

MARK FONDA

NASA/Ames Research Center, Mail Stop 239-4, Moffett Field, CA 94035

(Received 29 May 2000; Accepted 31 July 2000)

\begin{abstract}
All potential exogenous pre-biotic matter arrived to Earth by ways of our atmosphere, where much material was ablated during a luminous phase called "meteors" in rarefied flows of high (up to 270) Mach number. The recent Leonid showers offered a first glimpse into the elusive physical conditions of the ablation process and atmospheric chemistry associated with high-speed meteors. Molecular emissions were detected that trace a meteor's brilliant light to a 4,300 $\mathrm{K}$ warm wake rather than to the meteor's head. A new theoretical approach using the direct simulation by Monte Carlo technique identified the source-region and demonstrated that the ablation process is critical in the heating of the meteor's wake. In the head of the meteor, organic carbon appears to survive flash heating and rapid cooling. The temperatures in the wake of the meteor are just right for dissociation of $\mathrm{CO}$ and the formation of more complex organic compounds. The resulting materials could account for the bulk of pre-biotic organic carbon on the early Earth at the time of the origin of life.
\end{abstract}

Earth, Moon and Planets 82-83: 57-70, 2000.

(C)2000 Kluwer Academic Publishers. Printed in the Netherlands. 
Keywords: Ablation, astrobiology, exobiology, meteors, meteoroids, origin of life

\section{Introduction}

Accretion of extraterrestrial matter has long been of interest as a source of pre-biotic organic carbon for the origin of life on Earth (Oró, 1961; Sagan, 1974; Lewis et al., 1979; Anders, 1989; Pepin, 1991; Huebner and Boice, 1992; Delsemme, 1992; Chyba and Sagan, 1992, 1998; Oberbeck and Aggarwal, 1993; Chang 1993, Whittet, 1997; Oró and Lazcano, 1998). Most organic carbon is thought to be accreted by impacts of comets and primitive asteroids (Oró, 1961; Chyba et al., 1990). However, the high-speed impacts are expected to be so energetic that the ensuing fireball destroys virtually all molecular species in the impacting object and subsequent synthesis upon cooling in a $\mathrm{CO}_{2}$ rich atmosphere is not efficient (McKay and Borucki, 1997; Chyba and Sagan, 1998). Moreover, such impacts are infrequent and have strong perturbing effects on the pre-biotic environment at the time of delivery (Maher and Stevenson, 1988; McKinnon, 1989; Chyba, 1993).

Accretion of meteoroids is a more gentle and continuous mechanism for delivery of organic carbon species, especially in the case of the Interplanetary Dust Particles (IDP) that are collected mostly intact in the Earth's atmosphere. Among this collected debris of small solar system bodies there are chondritic IDPs with organic carbon abundances of about 10 mass percent on average (Anders, 1989; Gibson, 1992). The organic carbon contains complex aromatic molecules up to 500 a.m.u. (Clemett et al. 1993). However, all IDPs represent a small fraction $(<8$ $\%$ ) of the incoming mass, while low encounter velocities favor asteroidal particles that are relatively poor in organic carbon compared to cometary matter (Bradley et al., 1988). Comet Halley's dust has been measured to contain up to 50 mass percent refractory organics (Krueger and Kissel, 1987; Greenberg, 2000).

Here, we consider the possibility that meteors could have delivered organic carbon to the early Earth. Meteors are the luminous phase that represents the process of ablation and fragmentation of the meteoroids' interaction with the atmosphere. Of particular interest are those meteoroids that are too small to cause destructive high-pressure and high-temperature shock-induced chemistry (Menees and Park, 1976, Park and Menees 1978). 


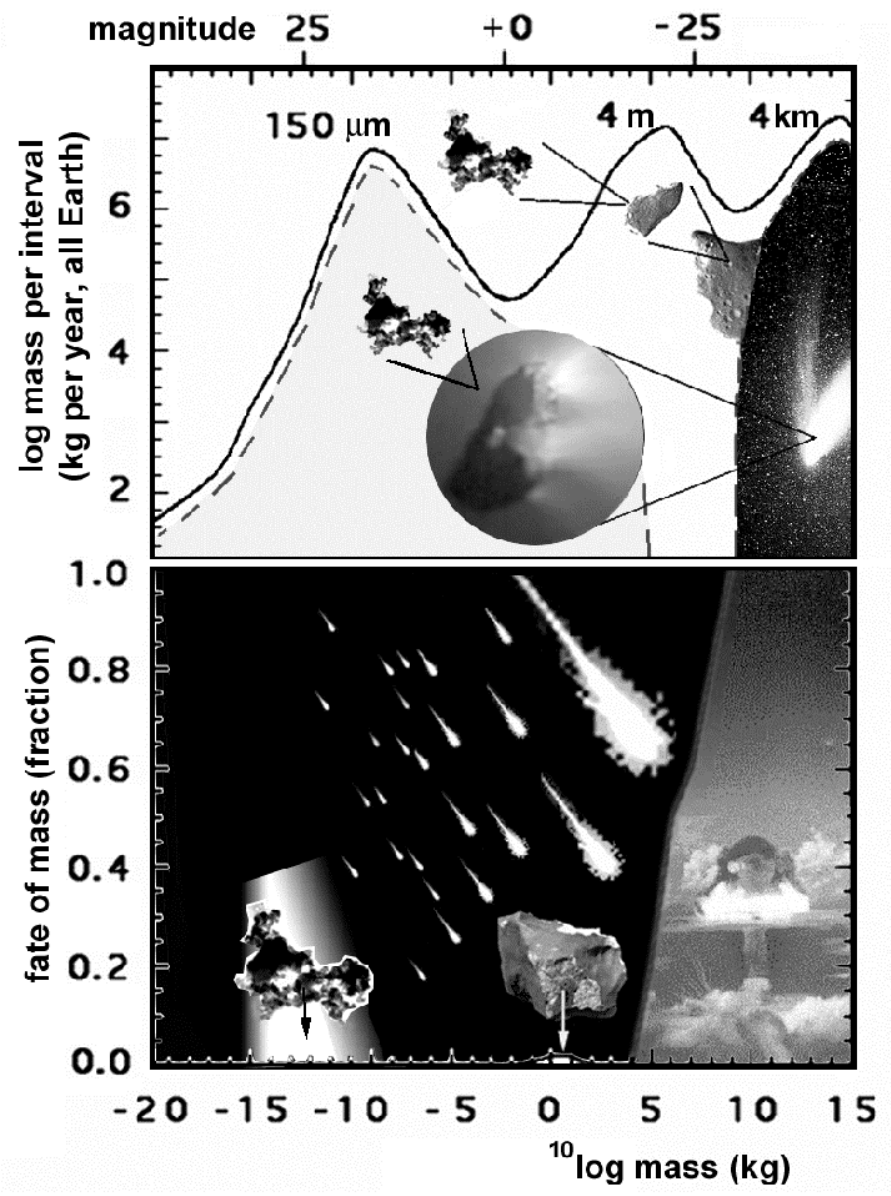

Figure 1. Top panel: the current annual (log) mass influx per unit (log) mass interval of all types of incoming matter in Earth's atmosphere, compiled from Love and Brownlee (1993) and Ceplecha (1992, 1994) Bottom panel: the fate of this matter upon accretion, as a fraction of the total. Fractions are derived from estimated meteorite yields (Oberst et al., 1998; Halliday et al., 1984: Bland et al., 1996), impact limit (Ceplecha, 1992, 1994), and entry heating (Flynn, 1989; Love and Brownlee, 1991), the latter for the new present-day velocity distribution (Taylor and Elford, 1998).

The fraction of mass of meteoroids that are too large and too fast to survive ablation, but too small to cause shock-inducted modification of the incoming meteoroid, is schematically shown in Figure 1. The figure shows the present annual mass influx per mass interval. The various 
sources of matter are identified. Impacts become progressively infrequent for more massive objects. The present-day distribution is thought to be representative of the dust influx on the early Earth, except that the relative contributions from asteroids and comets may have differed (Chyba and Sagan, 1998). The mass distribution has peaks at 150 microns (meteoroids), 4 meters (asteroid fragments and comet boulders), and $4 \mathrm{~km}$ (comets and asteroids). Meteoroids survive as IDPs or ablate during interaction with the atmosphere while in the molecular flow regime, and are recovered as micrometeorites that are mostly CMtype materials and lesser amounts of CI-type materials (Kurat et al., 1994; Engrand and Maurette, 1998). The shaded area reflects organicrich cometary dust. The meter-sized meteoroids lose most of their mass in the continuum flow regime, where they develop shocks because of their subsonic entry speeds. Some asteroidal fragments will survive as meteorites. Impacting comets and asteroids will catastrophically fragment in an airburst or explode upon impact (Chyba et al., 1990).

Based on this mass influx distribution, and the fate of accreting matter, we submit that meteoroids and small comet boulders can account for the bulk of the organic carbon on the early Earth - that is, if the survival of exogenous organic carbon, or the creation of reduced molecules by atmospheric chemistry, is efficient. Little is known about whether organic carbons can survive the meteor phase. Conditions of free molecular flow (in case the mean free path in air is larger than the typical dimensions of the object) and high Mach number conspire against theoretical and laboratory studies of meteoric plasmas. Factual information relies on remote sensing, to which few modern techniques have been applied.

Here, we report measurements of air plasma temperatures in the wake of meteors, which are compared to models of air plasma emission. The data are interpreted by means of direct simulation by Monte Carlo modeling of meteoroids in the free molecular flow regime. We conclude that meteors offer interesting pathways for the survival of organic carbon that warrant further study.

\section{Spectroscopy of Meteoric Plasmas}

We deployed from an airborne platform a new un-intensified slit-less CCD spectrograph for near-infrared and visible wavelengths at the time of the intense 1998 Leonid shower during the 1998 Leonid Multi- 
Instrument Aircraft Campaign (Jenniskens and Butow, 1999). The spectrograph consisted of a $600 \mathrm{l} / \mathrm{mm}$ grating, a Nikon f2.8/300 mm lens, and a Pixelvision two-stage thermoelectrically cooled 1024 x 1024 pixel CCD camera. The same spectrograph was used again to probe Perseid meteor spectra from a ground site in August of 1999. Our best spectra probe $1 \mathrm{~cm}$-sized meteoroids with entry velocities of $61 \mathrm{~km} / \mathrm{s}$ (Perseids) and $72 \mathrm{~km} / \mathrm{s}$ (Leonids) at altitudes $90-100 \mathrm{~km}$. The spectra cover part of the wavelength range $580-900 \mathrm{~nm}$ at a relatively high $0.5 \mathrm{~nm}$ resolution (Figures 2 and 3).

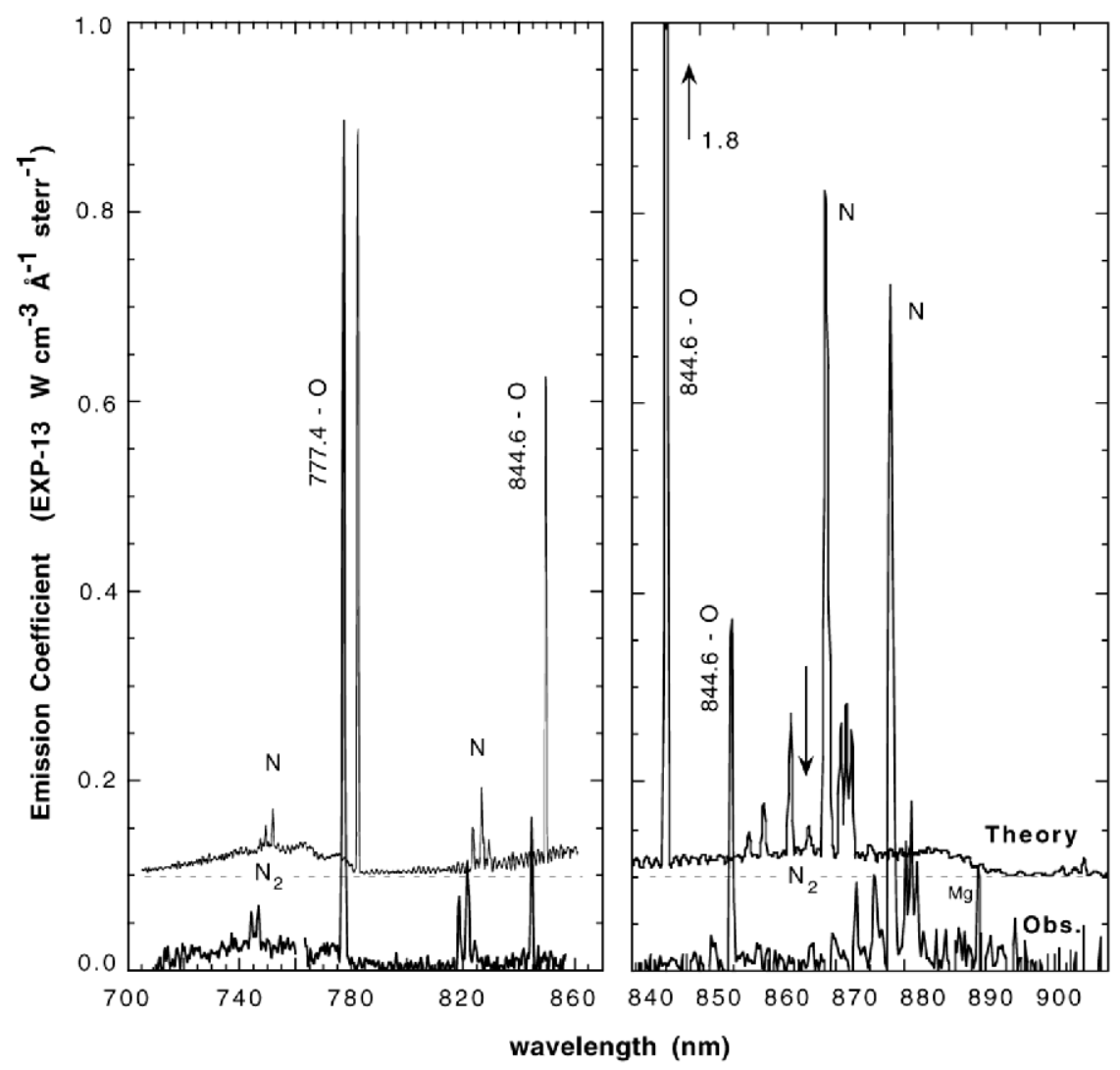

Figure 2. Two Leonid spectra from Nov. 17, 1998, at 17:47:06 UT (left) and 18:08:47 UT (right). The spectra are compared with NEQAIR2 model calculations, which is slightly displaced to facilitate comparison. Note the different line intensities of the OI line emission at $844.6 \mathrm{~nm}$ and the NI line emission at $865.6 \mathrm{~nm}$ (arrow). The line at $880.7 \mathrm{~nm}$ is of $\mathrm{MgI}$. 


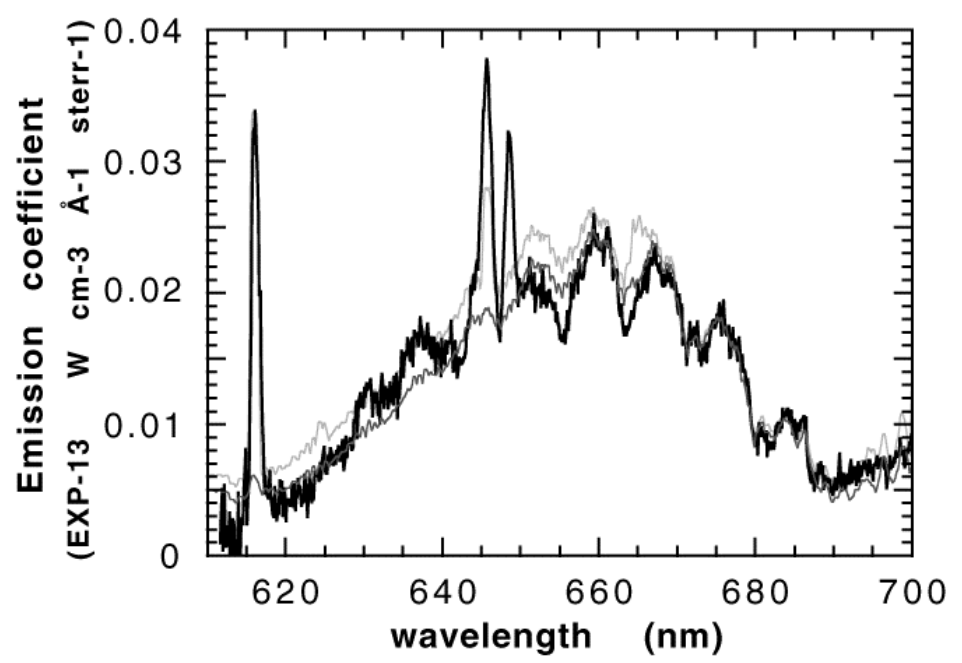

Figure 3. The $\Delta v=3$ first positive band of $\mathrm{N}_{2}$ as resolved in the spectrum of a magnitude -1 Perseid meteor from 00:25:26 UT, Aug. 13, 1999 (dark line). Emission lines at 615.7, 626.2, 645.4, and $665.4 \mathrm{~nm}$ are from atomic oxygen. The line at $648.9 \mathrm{~nm}$ may also be of OI. The two gray lines show the NEQAIR simulations at 4,300 $\mathrm{K}$ (dark, down) and 4,670 $\mathrm{K}$ (light, up), respectively. The simulation considers pure air $\left(79 \% \mathrm{~N}_{2}\right.$ and $\left.21 \% \mathrm{O}_{2}\right)$ at the standard atmosphere pressure of $\mathrm{P}=10^{-6} \mathrm{~atm}$ at the altitude of the meteor $(95 \mathrm{~km})$. The spectrum was convolved with a triangular slit function of FWHM $=0.5 \mathrm{~nm}$, which matches the line width measured on the observed spectra.

The dominant emission is from atmospheric lines of $\mathrm{O}$ and $\mathrm{N}$ and the first positive bands of $\mathrm{N}_{2}$, in contrast to prior studies at shorter wavelengths where the emission lines of ablated meteoric metal atoms dominate. The observed lines and bands are well matched by the NEQAIR2 radiation model of heated air in thermodynamic equilibrium (Park, 1985; Laux, 1993). The match implies that the bulk of emission is from gas in near thermal equilibrium despite the high Mach number flow. The observed ratio of atomic and molecular nitrogen in the Leonid spectra (Figure 2) is a sensitive measure of temperature and implies a chemical equilibrium temperature of $T_{c}=4,340 \pm 100 \mathrm{~K}$. The $\mathrm{N}_{2}$ band contour (and NI lines) of the Perseids are well matched by a simulation at $\mathrm{T}_{\mathrm{v}}=4,300 \pm 40 \mathrm{~K}$ (Figure 3). All values are similar to temperatures estimated from meteoric metal atom emission lines at $\mathrm{T}_{\mathrm{e}}=4,500 \pm 500 \mathrm{~K}$ (Borovicka et al., 1999). 
The data are sufficiently precise to recognize numerous signs of nonequilibrium behavior. There is excess emission at high $v$ levels in the $\mathrm{N}_{2}$ molecular band as a result of recombination processes (Figure 3 ). The OI line intensities are not always well matched (Figure 2). Notably, the OI line at $844.6 \mathrm{~nm}$ is a factor of 3 fainter than that calculated in all Leonid spectra and different from laboratory LTE air plasmas (Park et al., 1997, 1998), while OI lines between 600 and $700 \mathrm{~nm}$ are stronger (Figure 3). Also, the NEQAIR model with initial $0.03 \%$ atmospheric $\mathrm{CO}_{2}$ predicts $\mathrm{CN}$ emission comparable to the first positive $\mathrm{N}_{2}$ bands, but no $\mathrm{CN}$ (or isoelectric $\mathrm{N}_{2}^{+}$) is observed.

Another sign of non-equilibrium is the intensity of the OI $777.4 \mathrm{~nm}$ line emission. The measured intensity of the line, relative to the intensity of recorded background field stars, can be compared to the volume emission coefficient of the plasma in the model (vertical scales in Figure 2). From this, we derive a volume for the emitting gas of $1 \times 10^{13} \mathrm{~cm}^{3}$, assuming the gas is at 4,300 $\mathrm{K}$. Initial-train-radius theory predicts a volume of only about $3 \times 10^{7} \mathrm{~cm}^{3}$ for the head of the meteor (Jones, 1995).

\section{Theoretical Model of rarefied Flow}

The source region of the $\mathrm{T} \sim 4,300 \mathrm{~K}$ emission was identified using the direct simulation Monte Carlo (DSMC) technique, which was applied to the two-dimensional flow about a $1 \mathrm{~cm}$-sized Leonid meteor (density 1 $\mathrm{g} / \mathrm{cm}^{3}$ ). For many years DSMC has been developed and applied to a variety of rarefied flows (Dietrich and Boyd, 1996), but this is the first attempt to apply the technique to a computation of this type. Two cases were considered: one with no ablation, and another one with a simple Bronsten ablation model (Bronsten, 1983), in which the ablated material is assumed to be magnesium. In the case without ablation (Figure 4a), we find a rapid decline of temperatures outward, where multiple collisions quickly stop the accelerated air molecules. This is the process described by the initial meteor-train-radius theory, which in light of this model might still apply well to the near spherical source of radar head echoes (Jones, 1995).

Including meteor ablation result in dramatic changes when applying this model (Figure 4b). We find that ablation increases the flow field temperature around the meteor over an extended area in a wake behind the meteor, with elevated values around 5,000 K. 


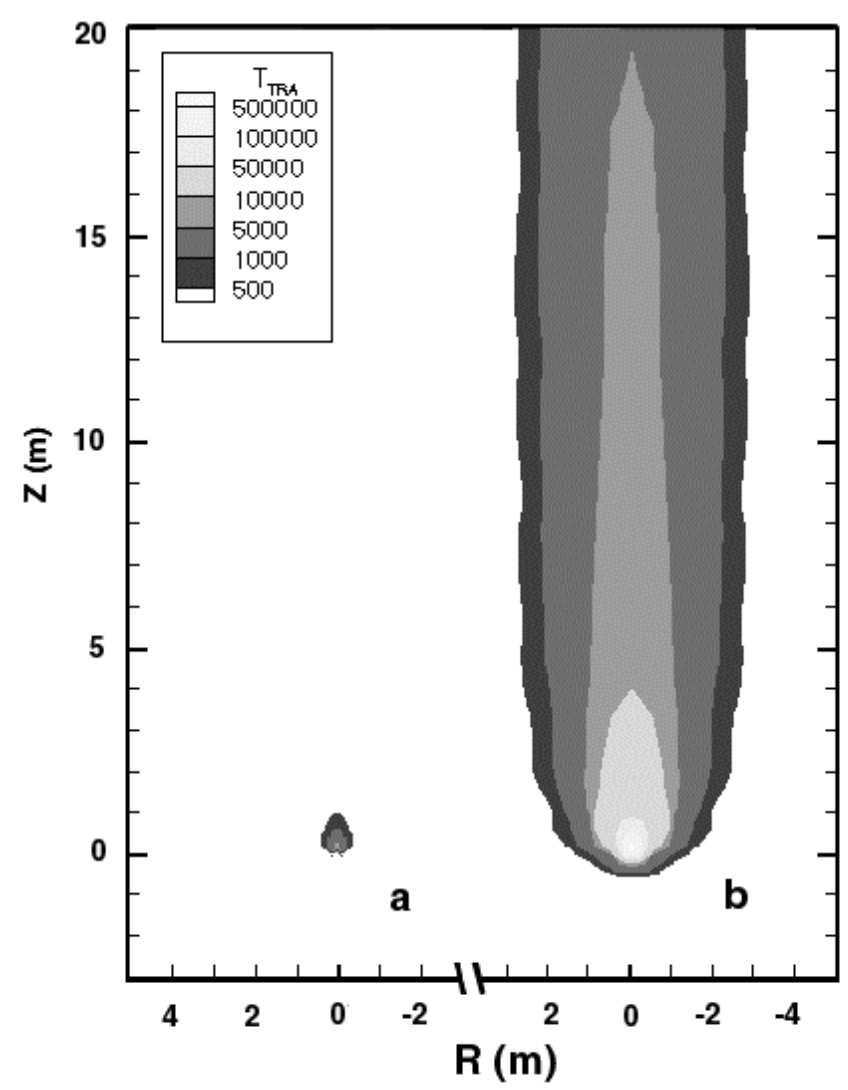

Figure 4. Translational temperature field from a rarefied flow model of a -1 magnitude Leonid meteor at $95 \mathrm{~km}$ altitude shown without ablation (a), and with ablation of $\mathrm{Mg}$ atoms (b).

The wake is caused by air molecules penetrating the skin of a dense plasma of ablated material in front of the meteoroid that collides with the meteoric plasma several times in a process of thermalisation. The collisions drive the meteoric ablation products and heated air past the meteoroid, where they expand into the meteor wake. The rotational temperatures are typically less than translational temperatures in the meteor's head but they equilibrate in the wake. We conclude that most of the observed meteor emission originates from this nearly equilibrated gas. 


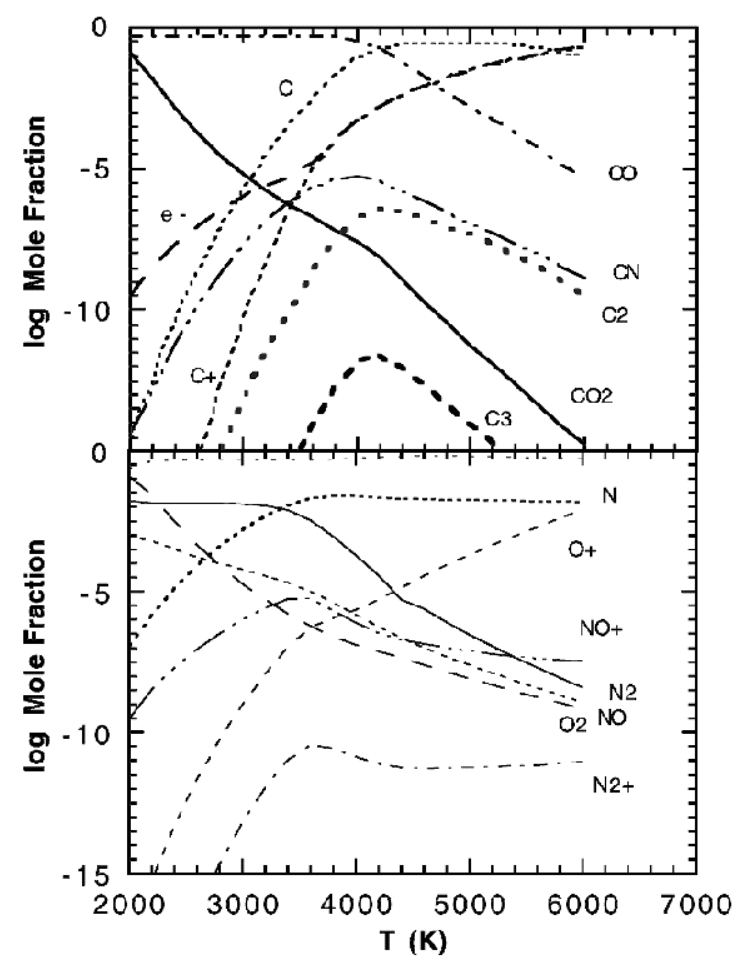

Figure 5. Molecular abundances for equilibrium air plasma at $95 \mathrm{~km}$ altitude (P $\left.=10^{-6} \mathrm{~atm}\right)$ in a range of Local Thermodynamic Equilibrium temperatures and for an assumed Mars-like early-Earth atmosphere of particle number composition $\mathrm{O}_{2} / \mathrm{CO}_{2} / \mathrm{N}_{2} / \mathrm{Ar} / \mathrm{CO}=0.13 / 95.32 / 2.7 / 1.6 / 0.08 \%$.

\section{The Delivery of Organic Matter to the early Earth.}

Interestingly, the study of fast shower meteors can help clarify a role of meteors in creating pre-biotic conditions on Earth, which involved a wide range of meteoroid masses and entry velocities. This is because the wake temperatures of all meteors are in the same narrow range of 3,900 $\pm 900 \mathrm{~K}$ as derived from the well studied meteoric metal atom emission lines (Borovicka and Bocek, 1995; Borovicka and Betlem; 1997; Harvey, 1973). There is no obvious trend with meteor magnitude (mass) or entry velocity. The observed Leonid spectra, too, do not change significantly with altitude or meteor brightness over the observed range. 
We submit that the mixing time-scale of air and ablation plasma does not vary much with meteor mass and velocity. Meteors represent two sources of pre-biotic carbon: a) Direct influx of organic carbon and metallic compounds in a rarefied high Mach number flow, and b) kinetic energy induced atmospheric chemistry involving $\mathrm{CO}_{2}$ and $\mathrm{N}_{2}$, which is also of interest to the issue of nitrogen fixation (Chyba and Sagan, 1998).

Our observations show that relevant atmospheric chemistry can occur in two regimes: (1) the extended wake of the meteors at temperatures of about 4,300 $\mathrm{K}$ and (2) at the interface layer between impinging air and ablation products at temperatures of about $10,000 \mathrm{~K}$. The $\mathrm{Mg}^{+}$emission line in bright meteors was traced to a component that increases in relative intensity at $\mathrm{T} \sim 10,000 \mathrm{~K}$ with meteor brightness and entry velocity (Borovicka, 1994). This component is due to meteoric vapor that builds up in front of the ablating meteoroid, rather than to the formation of a shock front as is commonly believed. In both cases, the not fully equilibrated chemical reactions occur at higher temperatures and longer time scales than in the 1-D equilibrium models by Menees and Park (1976) and Park and Menees (1978).

Unfortunately, no models are yet capable of reliably handling the types of non-equilibrium chemistry implied by our observations. An important find, however, is that the observed excitation temperatures are close to the dissociation equilibrium of $\mathrm{CO}$. As a result, our equilibrium chemistry simulation of the meteor plasma in a $\mathrm{CO}_{2}$ rich atmosphere (Figure 5) results in relatively high yields of potential pre-biotic molecules. This air composition may reflect that of the early Earth (Chyba and Sagan, 1998) and is certainly the least favorable case for reaction chemistry. Right at about $4200 \mathrm{~K}$ is where the production of linear carbon chains such as $\mathrm{C}_{2}$ and $\mathrm{C}_{3}$ peaks. Under these conditions, small amounts of aromatic hydrocarbons are expected to be formed upon cooling, as well as compounds rich in $\mathrm{C}=\mathrm{O}$ and $\mathrm{C}-\mathrm{N}$ groups. Such compounds could offer numerous chemical pathways to yield other reduced molecules of potential significance to the origin of life on the early Earth.

Finally, assuming organic compounds are common to Leonid meteoroids, the lack of observed $\mathrm{C}, \mathrm{C}_{2}$ and $\mathrm{CN}$ emission from the combustion of organic matter in the ablating meteoroids implies that organic compounds survive as large molecular fragments. It is possible that they are lost early in the meteor trajectory at low temperature $\mathrm{T}<$ $500 \mathrm{~K}$ when no optical emission occurs. However, meteors do not typically show differential ablation (Borovicka et al. 1999). This 
suggests that all mineral compounds are lost simultaneously irrespective of volatility in a process rather like sputtering by impinging meteoric ablation products instead of complete evaporation of the grain. Hence, most organic carbon, too, is expected to be lost at $80-110 \mathrm{~km}$ altitude under the physical conditions described in this paper.

Perhaps the survival of organic carbon is an analog with the common technique of laser induced desorption of large molecules, whereby they are only momentarily heated in a chemically reducing environment and subsequently quickly cooled by collisions with gas molecules and radiative cooling. For example, laser pulsed heating of aniline on a sapphire surface at $10^{8} \mathrm{~K} / \mathrm{s}$ leads to a peak surface temperature of 1,000 $\mathrm{K}$, but with aniline remaining intact at $360 \mathrm{~K}$ internal vibrational temperature (Maechling et al., 1996).

\section{Relevance of Delivery through Meteors}

At the time of the origin of life on Earth 4 Gyr ago, the mass influx of meteoroids was about 200 times the present day mass influx of $4 \times 10^{7}$ $\mathrm{kg} / \mathrm{yr}$ (Love and Brownlee, 1993). The factor of 200 follows from the lunar impact record and a linear scaling between meteoroids and parent bodies (Chyba and Sagan, 1998). Approximately half of this influx is thought to be carbon-poor asteroidal matter with at best 4 mass \% organic carbon in rare CI chondrites and the other half is carbon-rich (25-50 \%) cometary matter (Krueger and Kissel, 1987; Delsemme, 1991). Hence, meteors contributed at least $1 \times 10^{9} \mathrm{~kg} / \mathrm{yr}$ of organic carbon to the early Earth if all organic carbon survived the ablation process.

This outweighs the yield from all other exogenous and terrestrial sources of organic carbon on the early Earth as estimated in the recent review by Chyba and Sagan (1998). The main exogenous source, interplanetary dust particles, was estimated to yield at best only $2 \times 10^{8}$ $\mathrm{kg} / \mathrm{yr}$, because less than 8 mass percent of small <1 gram particles survive atmospheric entry heating (Figure 1). Meteorites are a negligible source because only 0.04 mass percent of matter $>1 \mathrm{~g}$ arrives to Earth in the form of meteorites (Oberst et al., 1998; Halliday et al., 1984; Bland et al., 1996). For even larger bodies, only negligible organic carbon survives the shock chemistry (Chyba and Sagan, 1998). Hence, meteors could account for at least $80 \%$ of all exogenous organic carbon.

A relatively high production yield of $\mathrm{C}_{2}$ and $\mathrm{CN}$ from atmospheric chemistry is derived from Figure 4. For a $\mathrm{CO}_{2}$ rich atmosphere, we 
calculate a yield of carbon of $1 \times 10^{-9} \mathrm{~kg} / \mathrm{J}$. For a total kinetic energy of $1 \times 10^{18} \mathrm{~J} / \mathrm{yr}$ from meteors $4 \mathrm{Gyr}$ ago, the yield is $1 \times 10^{9} \mathrm{~kg} / \mathrm{yr}$. This is only an upper limit because the chemical reactions are not expected to reach full thermodynamic equilibrium, which is supported by the absence of $\mathrm{CN}$ or $\mathrm{C}_{2}$ emission in the observed spectra.

On the other hand, alternative scenarios imply low yields as well. From organic residues at the $\mathrm{K} / \mathrm{T}$ boundary, the yield of organic carbon in giant impacts $4 \mathrm{Gyr}$ ago in a mildly reducing atmosphere has been optimistically estimated at only $2 \times 10^{8} \mathrm{~kg} / \mathrm{yr}$ (Chyba and Sagan, 1998).

Terrestrial sources are not much more efficient in this regard. Electric discharges contribute a mere $3 \times 10^{7} \mathrm{~kg} / \mathrm{yr}$ and UV photolysis by sunlight in a mildly reducing atmosphere can account for $3 \times 10^{8} \mathrm{~kg} / \mathrm{yr}$ (Chyba and Sagan, 1998). Furthermore, the analysis of effluents from bioorganically uncontaminated hot or cold springs has failed to show any organic molecules besides methane (Mojzsis et al., 1999).

That leaves meteors as a potential source for more than $2 / 3$ of the prebiotic organic carbon on the early Earth.

Of particular interest for future studies of meteors is the possible detection of ablated organic carbon by its 3.4-micron feature, as molecules in stratospheric aerosols, or indirectly from its interaction with the airglow chemistry. Additional Leonid storms are anticipated in November 2001 and 2002 (McNaught and Asher, 1999), when meteors may fill the sky again as frequently as they did at the time of the origin of life.

\section{Acknowledgements}

We are grateful for the constructive reviews by Jiri Borovicka, Kevin Zahnle, and an anonymous referee to improve the presentation of this paper. The spectrograph was developed with support of the NASA Ames Research Center Director's Discretionary Fund. The 1998 Leonid MultiInstrument Aircraft Campaign was NASA's first Astrobiology Mission. The campaign was made possible by grants from NASA's Exobiology program and the Advanced Missions and Technology Program for Astrobiology, as well as by NASA's Planetary Astronomy program, NASA Ames Research Center, and the U.S. Air Force. Editorial handling: Frans Rietmeijer. 


\section{References}

Anders, E.: 1989, Nature 342, 255-257.

Bland, P.A., Smith, T.B. and Jull, A.J.T., Berry, F.J., Bevan, A.W.R., Cloudt, S., Pillinger, C.T.: 1996, MNRAS 283, 551-565.

Borovicka, J.: 1994, Planet. Space Sci. 42, 145-150.

Borovicka, J. and Betlem, H.: 1997, Planet. Space Sci. 45, 563-575.

Borovicka, J. and Bocek, J.: 1995, Earth Moon, and Planets 71, 237-244.

Borovicka, J., Stork, R., and Bocek, J.: 1999, Meteoritics Planet. Sci. 34, 987-994.

Bradley, J.P., Sandford, S., and Walker, R.M., 1988, in J.F. Kerridge and M.S. Matthews (eds.), Meteorites and the Early Solar System, pp. 861-898, University of Arizona Press, Tucson, AZ.

Bronshten, V.A.: 1983, Physics of Meteor Phenomena, D. Reidel, Dordrecht, pp. 356.

Ceplecha, Z.: 1992, Astron. Astrophys. 263, 361-366.

Ceplecha, Z.: 1994, Astron. Astrophys. 286, 967-970.

Chang, S.: 1993, in J.M. Greenberg et al. (eds.), The Chemistry of Life's Origins, p. 259-299.

Chyba, C.F.: 1993, Geochim. Cosmochim. Acta 57, 3351-3358.

Chyba, C.F. and Sagan, C.: 1992, Nature 335, 125-132.

Chyba, C.F. and Sagan, C.: 1998, in P.J. Thomas, C.F. Chyba and C.P. McKay (eds.), Comets and the Origin and Evolution of Life, Springer Verlag, p. 147-173.

Chyba, C.F., Thomas, P.J., Brookshaw, L. and Sagan, C.: 1990, Science 249, 366-373.

Delsemme, A.H.: 1991, in R.L. Newburn, Jr. et al. (eds.), Comets in the Post Halley Era, Kluwer, the Netherlands, pp. 377-428.

Delsemme, A.H.: 1992, Origins of Life 21, 279-298.

Dietrich, S. and Boyd, I.D.: 1996, J. Comp. Phys. 126, 328-342.

Engrand, C., and Maurette, M.: 1998, Meteoritics Planet. Sci. 33, 565-580.

Flynn, G.J.: 1989, Icarus 77, 287-310.

Gibson, E.K.: 1992, J. Geophys. Res. 97, 3865-3875.

Greenberg, J.M.: 2000, Earth, Moon and Planets 82-83, 313-324.

Halliday, I., Blackwell, A.T. and Griffin, A.A.: 1984, Science 223, 1405-1407.

Harvey, G.A.: 1973, in C.L. Hemenway, P.M. Millman and A.F. Cook (eds.), Evolutionary and Physical Properties of Meteoroids, NASA SP 319, NASA, Washington D.C., pp. 103-129.

Huebner, W.F., and Boice, D.C.: 1992, Origins of Life 21, 299-316.

Jenniskens, P., and Butow, S. J.: 1999, Meteoritics Planet. Sci. 34, 933-943.

Jones, W.: 1995, MNRAS 275, 812-818.

Krueger, F.K. and Kissel, J.: 1987, Naturwissenschaften 74, 312-316.

Kurat, G., Koeberl, C., Presper, T., Brandstätter, F., Maurette, M., 1994, Geochim. Cosmochim. Acta 58, 3879-3904.

Laux, C.O.: 1993, 'Optical Diagnostics and Radiative Emission of High Temperature Air Plasmas', Ph.D. Dissertation, HTGL Report T288, Stanford University, CA.

Lewis J., Barshay S.S. and Noyes B.: 1979, Icarus 37, 190-206.

Love, S.G. and Brownlee, D.E.: 1991, Icarus 89, 26-43.

Love, S.G. and Brownlee, D.E.: 1993, Science 262, 550-553. 
Maechling, C.R., Clemett, S.J., Engelke, F. and Zare, R.N.: 1996, J. Chem. Phys. 104, 8768-8777.

Maher, K.A. and Stevenson, D.J.: 1988, Nature 331, 612-614.

McKay, C.P. and Borucki, W.J.: 1997, Science 276, 390-392.

McKinnon, W.G.: 1989, Nature 338, 465-466.

McNaught, R.H. and Asher, D.J.: 1999, WGN, Journal of the IMO 27, 85-102.

Menees, G.P. and Park, C.: 1976, Atmospheric Environment 10, 535-545.

Mojzsis, S.J., Krishnamurthy, R. and Arrhenius, G.: 1999, in R.F. Gesteland, T.R. Cech, J.F. Atkins (eds.), The RNA World, Second edition. Cold Spring Harbor Laboratory Press, cold Spring Harbor, NY, 709 pp., p. 1-47.

Oberst, J., Molau, S., Heinlein, D., Gritzner, C., Schindler, M., Spurny, P., Ceplecha, Z., Rendtel, J. and Betlem, H.: 1998, Meteoritics Planet. Sci. 33, 49-56.

Oberbeck, V.R. and Aggarwal, H.: 1993, Origins of Life \& Evol. Biosphere 21, 317-338.

Oró, J.: 1961, Nature 190, 389-390.

Oró, J., and Lazcano, A.: 1998, in P. J. Thomas, C. F. Chyba and C. P. McKay (eds.), Comets and the Origin and Evolution of Life, Springer Verlag, pp. 3-27.

Park, C.: 1985, Nonequlibrium Air Radiation (NEQAIR) Program: User's Manual, NASA TM 86707, July 1985.

Park, C. and Menees, G.P.: 1978, J. Geophys. Res. 83, 4029-4035.

Park, C.S., Newfield, M.E., Fletcher, D.G., Gökçen, T. and Sharma, S.P.: 1997, AIAA Paper 97-0990.

Park, C.S., Newfield, M.E., Fletcher, D.G., Gökçen, T. and Sharma, S.P.: 1998, J. of Thermophysics and Heat Transfer 12, 190-197.

Pepin, R.O.: 1991, Icarus 92, 2-79.

Sagan, C.: 1974, Origins of Life 5, 497-505.

Taylor, A.D., and Elford, W.G.: 1998, Earth Planets Space 50, 569-575.

Whittet, D.C.: 1997, Orig. Life \& Evol. Biosphere 27, 249-262. 